\title{
Impacto en el crecimiento económico de Nicaragua con la promoción y tecnificación de las MIPYMES
}

\author{
Br.Leonel Antonio Flores Méndez, Bra. Santiaga José Cuadra López,
} Br. Nelson Javier Ruiz Sotelo.

Facultad de Ciencias Económicas. ${ }^{1}$

Recibido 30 de abril-Aprobado 28 de octubre 2013.

\section{INTRODUCCIÓN}

En la presente investigación, se aborda todo lo relacionado con la tipología, características y naturaleza de las MIPYMES, donde se provee de una noción más clara de lo que son y la importancia que estas tienen en el país. De igual manera que se estudió su importancia, también se abordad la correspondiente problemática a las cuales estas se enfrentan, las que resultaron un campo muy amplio al cual se tendrá que intervenir con rapidez. Ejemplo de dicha problemática, es la localizan en el mercado informal, el cual es uno de los obstáculos a superar, la formalización de estas entidades, por otra parte la dificultad del acceso al crédito, la falta de sistemas de control, bajo nivel de escolaridad de los empleados en el sector MIPYMES, entre otros.

La importancia del estudio de dicho sector MIPYME, radica fundamentalmente en que estas son de interés nacional, dado que estas se desempeñan como gran fuente empleo y que al mismo tiempo representan medios de subsistencia para la mayoría de los habitantes de la nación. Estas paralelamente resultan ser una opción muy atractiva para al crecimiento sostenible y constante de la nación. Esto es debido a que las Micro y Medianas empresas son candidatas o aspirantes fuertes a grandes empresas con un alto nivel competitivo, que van afectar de formar directa el Stock de capital del país, haciendo que haya un mejor desenvolvimiento económico. Cabe aclarar que dicha investigación se realizó bajo los criterios investigativos actuales, con la jerarquización de los objetivos a alcanzar para poder así abordar las cuestiones más relevantes sobre el tema a estudiar, por ende, la estructura del trabajo es la convencional.

\section{MATERIALES Y MÉTODOS}

\section{Tipo de Investigación:}

Por su naturaleza este es un estudio fundamentalmente Explicativo-Descriptivo: Porque se analizó a las MIPYMES y su impacto en el crecimiento económico de la nación, tomando en cuenta que es uno de los motores fundamentales. Debido a la gran cantidad de entidades existentes en la Repúblico se hace difícil realizar una investigación que explore a profundidad sus articulaciones. Además cada entidad posee sus propios objetivos y herramientas para lograrlos.

\section{Método de Investigación:}

Los métodos que se aplicaran para desarrollar el siguiente trabajo investigativo son: el método analítico y deductivo. Ya que nos permite observar como ha venido evolucionando el comportamiento de las MIPYMES desde un punto de vista general. Este es un estudio fundamentalmente de campo y

\footnotetext{
${ }^{1}$ Trabajo dirigido por el maestro Uriel Soto Sáenz
} 
documental, ya que este se realizara bajo el método de conocimiento normativo y positivo, partiendo así a la recopilación de información y posteriormente procesarla, por lo que en última instancia se utilizara un método analítico el cual se empleara para dar una breve descripción del desenvolvimiento de las MIPYMES y su futuro desarrollo.

\section{Técnicas e Instrumentos para Recolectar la Información}

Para la recopilación de la información se utilizaron fuentes indirectas tales como: Publicaciones Oficiales, Memoria Anual (BCN), Nicaragua en Cifra (BCN), Anuario Estadístico 2009 (BCN), Coyunturas Económica y encuesta anules del BCN a las medianas y pequeñas empresas del sector industria, comercio y servicio. De estas fuentes primarias se utilizaron informes, boletines. Además publicaciones no oficiales tales como: periódicos, revistas económicas, libros, internet.

\section{RESULTADOS Y DISCUSIÓN}

\section{Perspectivas de las Micro, Pequeñas y Medianas empresas en Nicaragua 1.1.La Responsabilidad Social Empresarial (RSE) desde una perspectiva de MIPYME}

En este contexto, no resulta sorprendente comprobar por tanto que la mayor parte de las investigaciones y estudios existentes en el ámbito de la RSE se hayan dirigido a estas grandes empresas, mientras que la atención dedicada a las MIPYMES ha sido mucho menor. Sin embargo, y según la opinión de diversos estudiosos en la materia, la RSE entre las MIPyMES requiere de una visión distinta a la que normalmente se utiliza en el caso de las empresas grandes dado que, en definitiva, las "empresas pequeñas no se comportan necesariamente como pequeñas grandes empresas".

Así, las MIPyMES están sujetas a un conjunto de características propias e intrínsecas que las hacen muy diferentes de las empresas grandes y que por supuesto afectan tanto los contenidos como la extensión y naturaleza misma de sus actividades de RSE. En este sentido las MIPyMES latinoamericanas en general y las micro y pequeñas empresas en particular se caracterizan, entre otros aspectos, por una baja intensidad de capital, presencia de propietarios/ socios/familiares como mano de obra, estructura burocrática mínima, poder centralizado, dificultades para el acceso a financiación exterior o subordinación a grandes empresas

La influencia de estas características en la temática RSE puede resumirse en los siguientes aspectos:

- Las MIPyMES juegan un importante papel de carácter social, tanto por su papel como creadoras de empleo y amortiguadores del problema del desempleo (al ser particularmente intensivas en este factor), como por ser un instrumento de cohesión y estabilidad social al dar oportunidades de empleo (bien sea formal o informal) a colectivos escasamente cualificados.

- En la mayor parte de las empresas pequeñas, la propiedad y la gestión de la empresa se concentra en la figura del propietario-gerente (asistido a veces por otros miembros familiares), el cuál ocupa un rol estratégico de líder en la organización al concentrar la mayoría de las decisiones estratégicas.

Según algunos autores, esta característica permite explicar la influencia en una manera impensable entre las empresas grandes que las expectativas, deseos u objetivos propios y personales del propietario-gerente (o de la familia) tienen en las decisiones empresariales (entre ellas por supuesto las relativas a las actividades ligadas con la RSE).

- El supuesto generalizado en teoría económica de que la maximización de beneficios es un objetivo de toda empresa puede que no sea del todo cierto en el caso de las MIPyMES, por lo que en muchos casos estas, MIPyMES persiguen una rentabilidad "satisfactoria" que les garantice su 
viabilidad y al mismo tiempo que les permita dedicar parte de sus esfuerzos a otros objetivos ligados con razones altruistas, sociales o morales.

- También porque la mayor parte de las empresas pequeñas operan en mercados locales, lo que les permite operar con mayor libertad en sus decisiones de RSE al no estar expuestas a las críticas de los medios de comunicación y de la sociedad civil, mucho más pendientes de las actuaciones de las empresas grandes.

En cualquier caso, algunas de estas MIPyMES operan como subcontratistas de estas grandes empresas, las cuales a su vez son particularmente vigilantes de las actividades y estándares de sus suministradoras, por otro lado, las MIPyMES aparecen fuertemente ligadas con la suerte social y económica de sus comunidades geográficamente más próximas. Esto dado que la mayor parte de sus clientes y trabajadores proviene de su área geográfica próxima. De esta forma, la reputación de la empresa y su imagen como empleador, productor o actor en el ámbito local influyen ciertamente en su competitividad.

Especialmente en aquellas que requieren un planteamiento a medio y largo plazo o que no son percibidas como "estratégicas" o "básicas" para el negocio,( y algunas actividades medioambientales o ligadas con el desarrollo de la comunidad). Ligado con esto, es posible esperar que la situación económica y sus efectos cíclicos tengan un efecto muy importante en la implicación de las Pymes en actividades de RSE, especialmente en momentos de recesión económica.

No resulta por tanto sorprendente que, ante tales limitaciones de tiempo y personal, algunos autores sugieran que los gestores de las Pymes sean más "reactivos" que "proactivos" con relación a sus actividades de RSE, ya que la atención a las actividades nucleares de la empresa es siempre prioritaria para ellos.

Además, estas limitaciones explican las prevenciones que las Pymes tienen con relación a las actividades reguladoras que las Administraciones Públicas puedan desarrollar en el ámbito social o medioambiental, las cuales suponen un coste mayor para estas empresas en comparación a sus homólogas más grandes.

Sin embargo, esta visión optimista no debe hacer perder de vista que la existencia de estas fuertes relaciones personales puede hacer a la empresa especialmente vulnerable en el caso de, por ejemplo, la existencia de conflictos o disputas. ${ }^{2}$

\subsection{Fomento a la producción con valor agregado para el consumo nacional y la exportación}

Con esta perspectiva se busca que al menos una rueda de negocios anual realizada, más 2 Congresos Regionales de las MIPYMES y que 15,000 empresas habrán reducido el costo de sus productos y servicios. El $75 \%$ de las empresas participantes en el Programa PROMIPYME habrán incrementado sus ingresos en por lo menos 15\%. Para poder lograr esto se necesita una serie de líneas de acción particulares para cada tipo de empresa (Según su tamaño).

- Para la Pequeña y Mediana Empresa:

Facilitar el acceso a los bienes y servicios públicos, tales como infraestructura de apoyo a la producción, transformación y comercialización (energía, agua, caminos, carreteras, puertos, aeropuertos, comunicaciones, entre otros).

\footnotetext{
${ }^{2}$ Vives Antonio, Banco Interamericano de Desarrollo. Corral Antonio, IKEI Responsabilidad Social de la Empresa en las PyMEs de Latinoamérica.
} 
Impulsar el establecimiento de instalaciones productivas a nivel local con enfoque socioeconómico4 orientadas al desarrollo de la microempresa.

$>$ Desarrollo de proyectos y modelos de agro-negocios en los territorios para la búsqueda de inversiones.

- Para la Microempresa:

Asistencia técnica para la mejora productiva.

$>$ Impulsar el establecimiento de mecanismos de acceso a mercados (de insumo de venta de bienes y servicios) en condiciones competitivas y con economía de escala. Ejemplo: Ferias, salas de exhibiciones, ventas, entre otros.

$>$ Impulsar la renovación de tecnología productiva.

\section{CONCLUSIONES}

Este estudio ha mostrado la información sobre el sector de las micro, pequeñas y medianas empresas en Nicaragua, proporcionando información cuantitativa y estadística para respaldar las características discutidas en dicha investigación.

Los resultados arrojan que las MIPYMES representan la columna vertebral de la economía dado que son generadoras de empleo y aportan significativamente a la conformación del Valor Agregado Bruto y por ende representan un motor en la economía, ya que arrastra al resto de vagones del desarrollo.

Sin embargo hay que destacar que este sector es muy heterogéneo, tanto en el tipo de actividad económica donde las unidades productivas participan, como en el tipo de organización que adoptan. Las MIPYMES generan casi dos tercios del empleo, pero padece los efectos de la asimetría de la globalización y en su mayor parte se desempeña en condiciones de semi-subsistencia, concentrado en la demanda de los mercados internos y sin posibilidades de competir en los mercados de productos transables.

También se caracteriza por un alto grado de informalidad, que actúa como una limitación importante al momento de que las unidades productivas puedan participar o aprovechar las oportunidades creadas por las políticas públicas diseñadas para apoyarlas durante el periodo de crisis económica.

Las microempresas, especialmente aquellas formadas por auto-empleados, trabajadores por cuenta propia y organizaciones familiares presentan este tipo de limitaciones, lo que hace poco probable que puedan beneficiarse directamente de cambios en las políticas públicas o de los esfuerzos para expandir las facilidades crediticias a través de los bancos u otras instituciones formales de crédito.

\section{BIBLIOGRAFÍA}

Álvarez, G (2008, 19 de febrero) MIPyME indefensas en tema de competencia, El Nuevo Diario, Managua-Nicaragua.

Balda, J (2010, 18 de junio) Realidad de MIPYMES en Nicaragua, Grandes PYMES, ManaguaNicaragua.

López, M. (2010, 19 de febrero) Nicaragua impulsara PYMES exportadoras en 2010, Revista Mercados y tendencias, Edición Número 653.

Comité MIPYME Centroamericano (2007-2008). Propuesta de MIPYMES para la Negociación del Acuerdo de Asociación CA-UE, CONIMIPYME, Nicaragua.

Dietriech, M (2011, 22 de marzo) Reto para las Pymes en Nicaragua, Televicentro de Nicaragua, Edición Número 6652, Managua-Nicaragua.

Bolaños, E (2001, lunes 2 de abril) Competitividad de las Pymes está amenazada, La Prensa Edición Número 22329, Managua-Nicaragua. 
Banco Centroamericano de Integración Económica (BCIE) (2010), Estudio sobre el efecto de la crisis financiera mundial en las MIPyME AB y el impacto de las medidas anti-crisis en Centroamérica, Preparado por Fundemos Consultores, S.A.

Fonseca, R y Meléndez, M (2006, 28 de julio) MIPIMES el mayor empleador en Nicaragua, publicación de la Fundación Internacional para el Desafío Económico Global - FIDEG, Managua- Nicaragua. 